\title{
INTRODUCTION: SOMETHING HAS TO CHANGE
}

It would hardly be earth-shattering to say that policy and governance, quality, equity, participation and accessibility are clear concerns in educational provision, whether we are talking about primary, secondary, tertiary or nonformal and adult education. These themes were on the agenda at the Sixth International Conference on Adult Education (CONFINTEA VI) in Brazil, December 2009 and in the first-ever Global Report on Adult Learning and Education, published by the UNESCO Institute for Lifelong Learning and launched at that conference. (More on this later.) The articles in this edition of International Review of Education pick up the same motifs, although in other corners of the lifelong learning field.

There is a distinctly African flavour too to the contents of the edition. At CONFINTEA VI an impassioned plea was made by one of the speakers at the opening ceremony to pay special attention to the adult educational needs of Africa. Whether or not the reader views this collection of articles through the lens of adult education, they afford a chance for reflection on relevant and interesting topics. Nor should one treat this edition as of pertinence only to those working in or interested in Africa, a UNESCO priority area: many of the discussions go beyond the merely parochial, and have resonance elsewhere, both geographically and sectorally.

One of the most pressing matters raised at CONFINTEA VI was how to convince governments to commit a greater proportion of their education budgets to the historically neglected adult education sector. A measure of the difficulty in achieving this is borne out in the article by Edith Mukudi Omwami and Edmond J. Keller, which analyses government spending requirements in sub-Saharan Africa with respect to a sector which has had far more political clout in recent years - namely universal primary education. They show that, despite the established compelling policy case for universal primary education, countries are falling very short in meeting their commitments to it. The authors demonstrate that at current unit costs, countries need to borrow more money externally, or to take money away from other (specifically secondary and tertiary) education sub-sectors. What, then, are the prospects for adult education, which is still trying to secure a seat at the table? The question is one not only for ministries of education to consider, but also for national treasuries or exchequers: how to get a larger slice of a cake that already has consumers who are hungrier, particularly when the cake is already too small to feed everyone.

M. Najeeb Shafiq considers the features of targeted education voucher schemes which can encourage greater participation in education by people from poor households in developing countries. Such vouchers enable poor households to pay tuition fees for attending non-public schools, the logic 
being that the state is unlikely to set up schools in urban slums or rural areas. Whatever one may think of non-public schools, what the article examines is the kind of regulatory, support and financial infrastructures that must be in place for such schemes to work, taking into account educational quality, sustainability and equity of participation. There may be useful insights to glean for similar kinds of initiatives in non-formal education.

Extending the private education theme to tertiary level, Daniel S. Alemu's article draws attention to for-profit higher education institutions in Ethiopia. Prior to 1996 there had been no private universities at all (indeed there were only three higher education institutions in toto before 1991). Less than a decade later, there were 60, enrolling one in four higher education students. Such a rapid expansion, while opening up educational possibilities, may not be accompanied by increases in quality, especially since the prime motivation of the institutions is to generate financial surpluses. Students may be enrolled (and retained) not on the basis of academic ability but on ability to pay, which raises ethical questions about equity and accessibility.

Njora Hungi and Florence $W$. Thuku attempt to tease out the factors which affect reading achievement in 14 African school systems. They use a multilevel mathematical model, taking data from the Southern and Eastern African Consortium for Monitoring Educational Quality student assessment programme. Pupil-related variables were separated from school-related ones, with controls for interactions between these two broad categories. While the modelling is sophisticated, it gives a very good basis for policy recommendations, isolating the variables which appear to be the most significant predictors of reading achievement. Those who are responsible for policy-making in adult education may look on in awe at the data that is available and the analyses that can be performed. Information of this type and level of sophistication is lacking on any consistent basis in adult education, and part of the task for the next few years, post-CONFINTEA VI, is to build up data at national level to inform policy and to enable cross-country analysis.

The issue of late school entry also gets a thorough statistical treatment, in the article by Yuko Nonoyama-Tarumi, Edilberto Loaiza and Patrice L. Engle. They find that economic factors can play some part in families' decisions to send their children to school later than the statutory school entry age. There is a conscious trade-off between late entry and early completion. Looking at 38 countries, the authors caution that making comparisons is fraught with complications. They note, for example, that there has been a tendency in the past for researchers to conflate the terms "age of enrolment" and "age of entry". Commonly-used indicators such as net enrolment rate and net intake rate are hostage to the definitions and sources of data that exist in different countries. It is not so straightforward a matter to conduct international comparative education research.

In parenthesis, it should be said that this experience had been amply evident in the compilation of the Global Report on Adult Learning and Education, based on 154 national reports submitted by UNESCO Member States. 
The quality, depth and coverage of data varied enormously between countries. In some instances information was patchy or incomplete. Differing conceptual understandings of key terms, huge variations in methodologies and instruments used to collect data, and inconsistencies in their application limited the extent to which cross-national analysis could be conducted. As it is extremely problematic to make informed policy decisions without solid data, among the most welcome outcomes to emerge from CONFINTEA VI were the commitment to develop capacity and infrastructure within countries to monitor and evaluate adult education and to the setting-up of an international database.

Ishmael I. Munene and Sara J. Ruto explore in more depth one of the factors associated with late school entry, in their survey of educational opportunities for children in domestic labour in Kenya. They draw attention to a phenomenon regarded by some as distasteful, but nevertheless a daily reality. Christopher Johnstone and Heidi Corce recount how an NGO-sponsored programme to provide teacher training for deaf adults in Kenya has not only improved their job prospects but also provided a more effective means to teach deaf students. These last two papers illustrate that situational barriers to learning are extremely hard to overcome, and that it is necessary to continue bringing them to the attention of practitioners, academics and policymakers through the pages of journals such as the International Review of Education until concerted effort succeeds in surmounting them.

What of CONFINTEA VI itself? While the Conference can be declared a success, it is of course far too soon to say what the practical and political consequences will be, as the dust settles and people re-acquaint themselves with the immediate needs of their day-jobs. It will be quite some time before the next Conference, and the earnest hope is that it will not just be "business as usual" until then. What comes after the many fine words uttered and the amount of midnight oil burned? The Belém Framework for Action, adopted as the Conference resolution to advance the case for adult learning and education, has explicit commitment from Member States. "From rhetoric to action" was a key motto of the Conference, and UNESCO will certainly play its full role in pushing things forward. Donors and partner organisations should prepare to play their parts too. Translating all this into real action, with a tangible impact on people's lives, however, will be the metric by which the success of not only the Conference, but also of the political will of the assembled delegates, will be judged. We will get a chance for an early analytical reflection, as a post-CONFINTEA VI special edition of International Review of Education is planned for publication later in 2010. 